\title{
THE MANAGEMENT OF A POST-POLIOLYTIC PATIENT FOR MAJOR ABDOMINAL SURGERY
}

\author{
M. MinUCK, M.D. and R. S. LAMBIE, D.A. (ENG.) ${ }^{1}$
}

A SEVERELY haNDiCAPPED PATIENT was recently presented to us for a cholecystectomy. His disability posed an interesting problem in anaesthetic management, for he suffered from a complete residual paralysis of all four limbs, the abdominal wall, and the costal muscles as a result of acute poliomyelitis which he had contracted in August, 1953.

After perusal of the literature we were unable to find any details of preoperative, operative, and post-surgical management for this type of case. For this reason we feel that this presentation may be of interest. ${ }^{2}$

\section{CASE History}

The patient, a 52-year-old white male, was admitted to St. Boniface Hospital on November 11, 1957, with a diagnosis of cholelithiasis and chronic cholecystitis. He gave a typical history extending over two years, with increasing frequency of attacks of pain in the preceding few months.

His jrevious surgical history was as follows: an appendectomy in 1945, a gastrectomy in 1951, and a mastoid revision in April, 1953. All results were satisfactory.

In August, 1953, he developed acute anterior poliomyelitis which required management in a respirator for eight and a half months. Paralysis was permanent and complete, extending from $\mathrm{D}_{4}$ downwards. He was eventually discharged ir 1954.

Physical examination of the chest wall showed wasting of tie intercostal muscles. His diaphragmatic movement was good. The hung fields were clear. His vital capacity was $2,235 \mathrm{ml}$., or 58 per cent of his normal predicted value. His timed vital capacity was normal, indicating that his pulmonary insufficiency was due to muscular atony and not to bronchospasm. His maxımum breathing capacity was $476 \mathrm{~L} . / \mathrm{min}$ An X-ray of his chest showed left ventricular prominence, and elongation and broadening of the aorta. Linear atelectasis was noted at the left base, and there was evidence to suggest bronchiectasis in the left lower lung. Emphysematous bullae were noted in both apical regions, more marked in the right. Except for an elevated sedimentation rate (76, Westergren), his blood picture was normal.

\section{ANAESTHETIC MANAGEMENT}

For sedation, the night prior to operation, he was given Tuinal $100 \mathrm{mg}$, orally. One hour before the operation he received promethazine 50 , $\mathrm{mg}$., and atropine sulphate $0.4 \mathrm{mg}$. intramuscularly.

One litre of 5 per cent glucose in water was started intravenously. The patient was then induced with $150 \mathrm{mg}$. of thiopental sodium, followed by $15 \mathrm{mg}$. of succinylcholine. At the same time 100 per cent oxygen was delivered by mask. When paralysis was complete, the larynx was sprayed with 2 ml. of 2 per cent

1St B Bonfface Anaeșthetic Clinic, Winnipeg, Man.

${ }^{2}$ The authors wish to thank Dr S. S. Pelkoff for permission to discuss his patient in this paper. 
Pontocaine Hydrochloride ${ }^{\circledR}$, and intubated with a number 10 cuffed Magill endotracheal tube. He was maintained on a semi-closed system of nitrous oxide and oxygen, in a 4:2 litre mixture, and intermittent doses of thiopental. Small increments of succinylcholine were given to allow controlled respiration, using the Jefferson respirator. The latter was set to exert a positive pressure of $15 \mathrm{~cm} . \mathrm{H}_{2} \mathrm{O}$ and a negative pressure of $5 \mathrm{~cm} . \mathrm{H}_{2} \mathrm{O}$ at a rate of 20 per minute.

The small intermittent doses of thiopental were given to supplement the nitrous oxide in order to maintain the stage of analgesia. The eyelash reflex was present throughout the operation which lasted one hour and fifteen minutes.

A total of $400 \mathrm{mg}$. of a $2 \frac{1}{2}$ per cent solution of thiopental and $60 \mathrm{mg}$. of succinylcholine were used.

His pulse and blood pressure were recorded every five minutes. At the beginning of the operation the systolic pressure was $120 \mathrm{~mm}$. $\mathrm{Hg}$ and his pulse 100 per minute. Upon completion it was $110 \mathrm{~mm}$. $\mathrm{Hg}$ and 85 per minute. There were no fluctuations recorded during the procedure.

After the peritoneum was closed, one polyethylene tube was placed along the rectus sheath, and two others at each corner of the incision. The free ends were taped clear of the incision and dressing, and through each $5 \mathrm{ml}$. of a 2 per cent solution of Procaine were injected.

A $3 \mathrm{ml}$. mixture, containing $100 \mathrm{mg}$. of piperidine plus $1.0 \mathrm{mg}$. of levallorphan, was prepared; $1 \mathrm{ml}$. of this was given intramuscularly 25 minutes prior to the end of the operation.

After a careful supralaryngeal toilet, the endotracheal tube was removed. The patient was conscious but drowsy, and complained of moderate pain. A further $0.3 \mathrm{ml}$. of the piperidine-levallorphan mixture was given intravenously.

Over a period of 6 minutes $150 \mathrm{mg}$. of B-methyl B. ethylglutamide (Megimide) were given intravenously. Very shortly after the administration of this drug the patient was completely awake, exhibiting no drowsiness, and showed return of his usual diaphragmatic excursions. The patient was transferred to the postanaesthetic room in excellent condition.

\section{Postoperative Management}

For the control of pain the patient received the following drugs: (a) $5 \mathrm{ml}$. of 2 per cent Procaine were injected into each of the polyethylene tubes-this was required approximately every 4 hours; (b) Piperidine $50 \mathrm{mg}$. plus $0.5 \mathrm{mg}$. of levallorphan-this was needed 15 times throughout the 16 days of postoperative period.

To combat pulmonary complications, aminophylline suppositories, bronchodilators, and physiotherapy were continued throughout the postoperative period.

Arterial blood $\mathrm{pH}$ and $\mathrm{CO}_{2}$ content and $\mathrm{CO}_{2}$ tensions were determined on the first and second postoperative days and found to be within normal limits. On the fourteenth day the vital capacity and maximum breathing capacity were somewhat reduced, compared with the preoperative record.

The patient was discharged sixteen days after his operation. 


\section{Discussion}

The marginally existing patient, such as we have here, is intolerant of any further discomfort or pain, superimposed upon his present disability. $\mathrm{He}$ is naturally much concerned about the outcome of his proposed major surgery. $\mathrm{He}$ is psychologically and physically an anaesthetic challenge (1).

The problem was to decide what anaesthetic technique would allow surgical intervention with the minimum of physiological imbalance, particularly of the respiratory system, and allow pain-free normal respiratory function in the postoperative period.

Crasilneck has suggested hypnosis or hypno-analgesia be used in such cases (2). Although we feel that hypnosis has a definite role in anaesthesia, we did not think that this particular patient was suitable for hypnosis nor was our experience in this method sufficient.

Explanation and assurance did not remove a deep-seated anxiety concerning his operation. For this reason, plus the usual contraindications for high spinal or epidural analgesia, these regional techniques were thought to be unsuitable (3) Thiopental was used for induction in order to avoid excitement and psychological trauma and further to ensure a smooth induction. Nitrous oxide was the obvious chorce of inhalational agent for it is non-explosive and non-irritative, and can be used in high flows with the Jefferson respirator. Our aim was not to establish anaesthesia but to remain in plane 3 of the stage of analgesia (4). Ideally, verbal contact should be upheld in order to be certain that the patient is in analgesia. In this case slight movements of the facial muscles were present, as well as a somewhat reduced eyelash reflex. Through previous experience these signs were presumptive evidence of analgesia. Several workers have demonstrated the value of this anaesthetic technique especially for the poor risk and geriatric case $(5,6)$. It has been found that there is minimal depression of the cardiovascular and central nervous systems, with marked reduction in reflex activity (7).

The small dose of succinylcholine was sufficient to allow smooth endotracheal intubation, and controlled respirations with the Jefferson respirator. As the total dose was $60 \mathrm{mg}$., there was little likelihood of immediate, postoperative respiratory depression.

Some may object to the use of Megimide in the attempt to reverse the effect of thiopental, and it is admitted that there is a great deal of controversy concerning the exact mechanism of Megimide. Recent studies have suggested its use to "reverse", thiopental anaesthesia, and have demonstrated its clinical advantage $(8,9)$. One of us (R. S. L.) used this drug to reverse buthalitone sodium anaesthesia on out-patients almost daily for one year with excellent results. Doses from $500 \mathrm{mg}$. to $1,000 \mathrm{mg}$. of buthalitone were counteracted by doses of $50 \mathrm{mg}$. to $200 \mathrm{mg}$. of Megimide. This drug is probably not a specific barbituate antagonist, but in some way it performs its counteraction by central stimulation. This action is unlike that of analeptics, which raise the blood pressure and induce hyperpyrexia. There can be no doubt concerning its dramatic effect upon reflex activity and respiration following barbiturate anaesthesia, which was clearly demonstrated with this patient. 
After the operation the patient immediately gave verbal indication of our next problem: the control of his postoperative pain. It was realized that if the usual dose of narcotic was used the tidal volume would be seriously reduced; on the other hand, if it was withheld, the vital capacity would still be reduced through splinting of the diaphragm.

Eckenhoff has pointed out that it is important in the patient with normal respiratory function to avoid the development of respiratory acidosis (10). In this case it was vital to avold tidal volume reduction either by under- or by oversedation.

Several opiate antagonists have recently been synthesized, and we have had the opportunity to use levallorphan tartrate (Lorfan ${ }^{8}$ ) in conjunction with narcoticsupplemented anaesthesia, and also in the postoperative period. Although the mode of action of these antagonists has not been clarified, reports show that they do reverse the respiratory depression $(11,12)$. These drugs, we feel, are a great step forward in the endeavour to allow pain to be relieved without the concomitant res ?iratory depression.

For the first two days after the operation local wound analgesia was successfully achieved by the already described polyethylene tube irrigation: $33.3 \mathrm{mg}$. of piperidine combined with $0.33 \mathrm{mg}$. of levallorphan were administered 5 times in the first 48 hours after the operation. We felt that this small amount of narcotic given for pain relief indicated the efficacy of the wound analgesia.

The authors realized that the major problem would arise in the postoperative period when depressive analgesia would be necessary to control severe pain. A tank respirator was kept on the ward should it become necessary, but at no time did the patient's condition warrant its use.

\section{SUMMARY}

The anaesthetic management of a severely handicapped post-poliomyelitic patient for major surgery has been described. The method is described in detail, with comment on the operative and postoperative management.

Emphasis has been placed on a rapid return to consciousness following surgery, and to pain-relief from the abdominal wound without respiratory depression. This was accomplished by two methods: (a) irrigation of the wound with local anaesthetic solution as required, $(b)$ the use of a Pethidine-Lorfan mixture ${ }^{3}$

\section{RÉSUMÉ}

Nous avons essayé de présenter la technique anesthésique et le ménagement post-opératoire d'un patient atteint d'une sevère insuffisance pulmonaire et dont l'état nécessitait une cholécystectomie.

L'insuffisance pulmonaire de ce patient est le résultat de la poliomyélite subie en 1953. L'examen médical et les études sur la fonction pulmonaire ont révélé la diminution de sa capacité vitale et respiratoire.

\footnotetext{
3This mixture is now avalable in a ready-mixed ampoule, Pethlorfan ${ }^{8}$.
} 
L'anesthésie se composait de Pentothal, de nitride oxide, d'oxygène et de meperidine. L'effect dépressant de Pentothal a été reversé par Megimide, l'indésirable action de meperidine sur la respiration a été reversé par levallorphan. Succinyl choline HCl a été employé pour obtenir la relaxation musculaire.

Les soins post-opératifs qui impliquaient le soulagement de la douleur sans toutefois réduire davantage le capacité vitale du patient ont été administrés de la façon suivante: $(a)$ les cathéters polyethelene, qui étaient placés dans lincision lorsque celle-ci fut close, ont été irrigés avec $2 \%$ de Procaine; $(b) 50 \mathrm{mg}$. de meperidine plus $0.5 \mathrm{mg}$. de levallorphan ont été administrés pour le douleur. Finalement une vigoureuse physiothérapie a été administré.

La guérison s'est produite sarıs imprévus et l'étude post-opérative de la fonction pulmonaire n'a indiqué aucurie signifiante réduction comprarée à celle faite d’avant l'opération.

\section{REFERENCES}

1. Joos, Thad H., et al. Risk of Surgery in Poliomyelitis Patients Dependent on Respirators. J.A.M.A. 161: 10 (1956).

2. Crasilneck, Harold B., et al. Special Indications for Hypnosis as a Method of Anaesthesia. J.A.M.A. 162: 18 (1956).

3. BonicA, J. J., et al. Perıdural Block. Analysis 3,637 Cases and a Review. Anesthesiology 18: (5) 723 (1957).

4. Artusro, J. F. Ether Analgesia durng Major Surgery. J.A.M.A. 157. 33-36 (1955).

5. Lambie,.R. S. General Analgesia for Major Surgery. To be published.

6. Heller, M. L., \& Watson, T. R. Analgesia with Nitrous Oxide-Oxygen-Curare for Major Surgery in the Poor Risk Patient. J.A.M.A. 161: 16 (1956).

7. Zweifash, B. W., \& Rubenstein, E. A. Effects of Depth of Anaesthesia on Behaviour of Peripheral Vascular Bed. Anesthesiology 14:"3 (1953).

8. Wyke, B. D, \& Frayworth, E. Use of Bemegride in Terminating Barbiturate Anaesthesià, Lancet' 1025 (November 23, 1957).

9. HARris, T. A. B. A Barbiturałe Antagonist. Lancet 181 (January 22, 1955).

10. Eckenhoff, J. E., et al. Respiratory Hazards of Oprates and Other Narcotic Analgesics. Surg, Gynec. \& Obst. 101: 701-708 (1955).

11. Machaj, T. S., \& Foldes, F. F. The Use of Narcotic Antagonsts in Anaesthesiology. Pennsylvania M. J. 59: 571 (May, 1956).

12. Eckentoff, J. E, et al. Observations on the Use of the Opiate Antagonists Nalorphıne and Levallorphan. Am. J. Med. Science 228: 546 (November, 1954).

13. Megirian, R, et:al. Alphaprodine Hydrochloride with Levallorphan Tartrate PostOperatively. Anesthesiology 18 (4): 610 (July, 1957). 